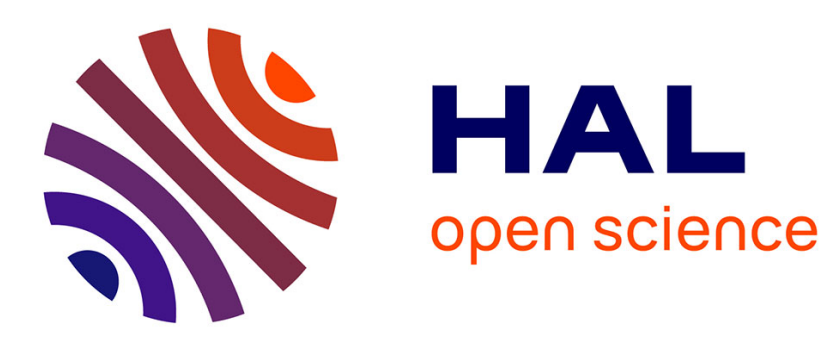

\title{
A beam finite element for through cracked tubular node behaviour modelling
}

\author{
A. Rouhan, Christian Wielgosz
}

\section{To cite this version:}

A. Rouhan, Christian Wielgosz. A beam finite element for through cracked tubular node behaviour modelling. Communications in Numerical Methods in Engineering, 2002, 18 (8), pp.555-564. 10.1002/cnm.512 . hal-01004676

\section{HAL Id: hal-01004676 \\ https://hal.science/hal-01004676}

Submitted on 3 Dec 2016

HAL is a multi-disciplinary open access archive for the deposit and dissemination of scientific research documents, whether they are published or not. The documents may come from teaching and research institutions in France or abroad, or from public or private research centers.
L'archive ouverte pluridisciplinaire HAL, est destinée au dépôt et à la diffusion de documents scientifiques de niveau recherche, publiés ou non, émanant des établissements d'enseignement et de recherche français ou étrangers, des laboratoires publics ou privés. 


\title{
A beam finite element for through-cracked tubular node behaviour modelling
}

\author{
A. Rouhan and C. Wielgosz \\ Laboratoire de Génie Civil de Nantes Saint-Nazaire, 2 rue de la Houssinière, \\ B.P. 9220844322 Nantes Cedex 3, France
}

This paper deals with the problem of a through-cracked tubular joint behaviour modelling. A new beam finite element has been created, in order to take into account the loss of stiffness of the joint due to through-thickness crack presence, and the coupling between axial force and bending momentum. This allows to study at a low computing time large damaged offshore structures, using beam elements. The mechanical model used to build the finite element is first described. An analytical identification of its internal parameters (eccentricity and stiffness) is then performed. Finally, some results are presented.

KEY WORDS: hybrid finite element; tubular assembly; through-crack; offshore structures

\section{INTRODUCTION}

Jacket offshore structures experience harsh loading conditions, leading to fatigue crack growth, mainly at the tubular nodes. Considering new cheap and promising underwater inspection techniques detecting only through-cracks, one may be able to predict the mechanical behaviour of such fast propagating cracks. Jacket structures involve lots of tubular members and are thus generally modelled using beam finite elements to reduce computational time. In that case, the use of classical beam finite elements supposes a rigid local behaviour of the joint. Concerning the real elastic behaviour of tubular nodes, some work to model noncracked tubular joints using a global flexibility matrix has already been done [1-3]. However, the mechanical behaviour of through-cracked nodes differ from a non-damaged one. Through-cracks are very large [4], giving an important increase in terms of flexibility [5]. It also shows a new effect due to the local geometry changes induced by the crack presence: a coupling between the bending momentum and the axial loading. In order to take into 
account these effects and to study the issue of the behaviour of the complete structure, a new cracked beam finite element is developed.

The finite element is based on a mechanical modelling of cracked joints. The method to compute the stiffness matrix of a $2 \mathrm{D}$ model is presented. It is mainly based on the complementary virtual principle. Then follows the complete description of the finite element building. As the model includes unknown mechanical parameters (eccentricity and stiffness), an identification scheme is proposed, using the least-squares method. Finally, results issued from the identification are presented and discussed. A T-joint with in-plane loading is chosen for illustration.

\section{SIMPLIFIED MODEL DESCRIPTION}

The local behaviour of a through-cracked node shows a bending momentum/axial load coupling, and stiffness loss at the welded connection. Considering a T-joint case with a throughcrack, only the brace tubular part is of interest: it is assumed to be clamped at the chord wall at $A$ (Figure 1). Thus, the coupling is modelled by an eccentricity $e$ (geometrical parameter), the loss of stiffness featured by a spiral spring with stiffness $k$. The behaviour of the other part (the brace beam) with length $l$, is the bending stiffness EI, and the axial stiffness ES. This model is an associated isostatic model of the free beam one, preventing any rigid body motion. The following developments are issued from References [6, 7]. The global stiffness matrix element $\mathbf{K}_{\mathrm{r}}$ of this isostatic model is obtained by inverting the compliance matrix $\mathbf{S}_{\mathrm{r}}$.

Let us denote by $\mathbf{U}_{\mathrm{c}}$ the displacement vector at nodes $A$ and $C$ (free element displacement vector), and $\mathbf{U}_{\mathrm{r}}$ the displacement vector at node $C$ (isostatic element displacement vector):

$$
\mathbf{U}_{\mathrm{c}}=\left[\begin{array}{c}
\mathbf{U}_{A} \\
\mathbf{U}_{C}
\end{array}\right], \quad \mathbf{U}_{\mathrm{r}}=\left[\mathbf{U}_{C}\right]
$$

$\mathbf{F}_{\mathrm{c}}$ is the force vector at nodes $A$ and $C$ (free element force vector) and $\mathbf{F}_{\mathrm{r}}$ the force vector at node $C$ (isostatic element force vector):

$$
\mathbf{F}_{\mathrm{c}}=\left[\begin{array}{c}
\mathbf{F}_{A} \\
\mathbf{F}_{C}
\end{array}\right], \quad \mathbf{F}_{\mathrm{r}}=\left[\mathbf{F}_{C}\right]
$$

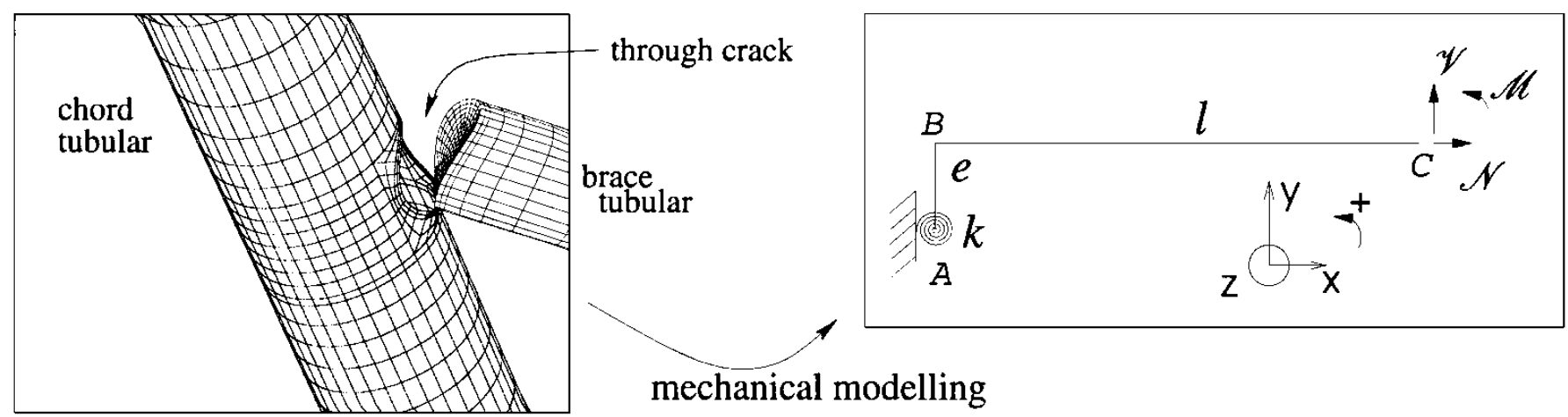

Figure 1. Scheme of the simplified model. 
The fundamental static principle gives the relationship between $\mathbf{F}_{\mathrm{c}}$ and $\mathbf{F}_{\mathrm{r}}$ :

$$
\mathbf{F}_{\mathrm{c}}=\mathbf{B F}_{\mathrm{r}}
$$

where $\mathbf{B}$ is a matrix. One looks now for the $\mathbf{U}_{\mathrm{c}}$ against $\mathbf{U}_{\mathrm{r}}$ relationship. When a virtual force vector $\delta \mathbf{F}_{\mathrm{r}}$ is applied at $C$, we have $\delta \mathbf{F}_{\mathrm{c}}=\delta \mathbf{B F}_{\mathrm{r}}$ : this relationship defines a static admissible force field. Using this virtual force vector, the equality between the complementary virtual work for the free element $\delta \mathscr{T}_{\mathrm{c}}$ and the associated isostatic one $\delta \mathscr{T}_{\mathrm{r}}$ is given by

$$
\forall \delta \mathbf{F}_{\mathrm{r}} \quad \delta \mathscr{T}_{\mathrm{c}}=\delta \mathbf{F}_{\mathrm{c}}^{\mathrm{T}} \mathbf{U}_{\mathrm{c}}=\delta \mathbf{F}_{\mathrm{r}}^{\mathrm{T}} \mathbf{B}^{\mathrm{T}} \mathbf{U}_{\mathrm{c}}=\delta \mathscr{T}_{\mathrm{r}}=\delta \mathbf{F}_{\mathrm{r}}^{\mathrm{T}} \mathbf{U}_{\mathrm{r}}
$$

and leads to

$$
\mathbf{B}^{\mathrm{T}} \mathbf{U}_{\mathrm{c}}=\mathbf{U}_{\mathrm{r}}
$$

The equality between the strain energy for the free beam and the isostatic beam element, using Equations (3) and (5) gives

$$
\begin{aligned}
\mathscr{E}_{\text {ISO }} & =\frac{1}{2} \mathbf{U}_{\mathrm{r}}^{\mathrm{T}} \mathbf{K}_{\mathrm{r}} \mathbf{U}_{\mathrm{r}}=\frac{1}{2} \mathbf{U}_{\mathrm{c}}^{\mathrm{T}}\left(\mathbf{B} \mathbf{K}_{\mathrm{r}} \mathbf{B}^{\mathrm{T}}\right) \mathbf{U}_{\mathrm{c}} \\
& =\mathscr{E}_{\text {FREE }}=\frac{1}{2} \mathbf{U}_{\mathrm{c}}^{\mathrm{T}} \mathbf{K}_{\mathrm{c}} \mathbf{U}_{\mathrm{c}}
\end{aligned}
$$

The relationship between the two stiffness matrixes is

$$
\mathbf{K}_{\mathrm{c}}=\mathbf{B} \mathbf{K}_{\mathrm{r}} \mathbf{B}^{\mathrm{T}}
$$

The matrix $\mathbf{K}_{\mathrm{r}}$ is related to the compliance matrix by

$$
\mathbf{K}_{\mathrm{r}}=\mathbf{S}_{\mathrm{r}}^{-1}
$$

By neglecting the shear stress-strain energy, the isostatic complementary strain energy is expressed as

$$
\mathscr{E}_{\mathrm{ISO}}^{c}=\frac{1}{2} \int_{0}^{l} \frac{\mathscr{N}^{2}(x)}{\mathrm{ES}} \mathrm{d} x+\frac{1}{2} \int_{0}^{l} \frac{\mathscr{M}^{2}(x)}{\mathrm{EI}} \mathrm{d} x+\frac{1}{2} \frac{\mathscr{M}_{1}^{2}}{k}
$$

where $\mathscr{M}(x)$ is the bending momentum, $\mathscr{N}(x)$ the axial load, and $\mathscr{M}_{1}$ the momentum at the clamped end $A$. The shape functions $\mathbf{N}_{i}(x)$ of the equilibrium finite element are obtained by expressing the internal forces as functions of $\mathbf{F}_{\mathbf{r}}$ :

$$
\left[\begin{array}{c}
\mathscr{N}(x) \\
\mathscr{M}(x) \\
\mathscr{M}_{1}(x)
\end{array}\right]=\left[\begin{array}{l}
\mathbf{N}_{1}(x) \\
\mathbf{N}_{2}(x) \\
\mathbf{N}_{3}(x)
\end{array}\right] \mathbf{F}_{\mathrm{r}}=\left[\begin{array}{ccc}
1 & 0 & 0 \\
0 & l-x & 1 \\
-e & l & 1
\end{array}\right]\left[\begin{array}{c}
\mathscr{N} \\
\mathscr{V} \\
\mathscr{M}
\end{array}\right]
$$


The complementary strain energy becomes

$$
\begin{aligned}
\mathscr{E}_{\mathrm{ISO}}^{c} & =\frac{1}{2} \mathbf{F}_{\mathrm{r}}^{\mathrm{T}}\left(\int_{0}^{l} \frac{\mathbf{N}_{1}^{\mathrm{T}}(x) \mathbf{N}_{1}(x)}{\mathrm{ES}} \mathrm{d} x+\int_{0}^{l} \frac{\mathbf{N}_{2}^{\mathrm{T}}(x) \mathbf{N}_{2}(x)}{\mathrm{EI}} \mathrm{d} x+\frac{\mathbf{N}_{3}^{\mathrm{T}}(x) \mathbf{N}_{3}(x)}{k}\right) \mathbf{F}_{\mathrm{r}} \\
& =\frac{1}{2} \mathbf{F}_{\mathrm{r}}^{\mathrm{T}} \mathbf{S}_{\mathrm{r}} \mathbf{F}_{\mathrm{r}}
\end{aligned}
$$

and gives the compliance matrix of the isostatic element:

$$
\mathbf{K}_{\mathrm{r}}^{-1}=\mathbf{S}_{\mathrm{r}}=\int_{0}^{l} \frac{\mathbf{N}_{1}^{\mathrm{T}}(x) \mathbf{N}_{1}(x)}{\mathrm{ES}} \mathrm{d} x+\int_{0}^{l} \frac{\mathbf{N}_{2}^{\mathrm{T}}(x) \mathbf{N}_{2}(x)}{\mathrm{EI}} \mathrm{d} x+\frac{\mathbf{N}_{3}^{\mathrm{T}}(x) \mathbf{N}_{3}(x)}{k}
$$

\section{3D FINITE ELEMENT DESCRIPTION}

The way to build the beam finite element has been presented in the previous section. It was supported by a 2D example. One should now consider a 3D beam finite element, with a through-crack at both nodes (Figure 2). Cracks are oriented in the plane perpendicular to the beam element axis, leading to the introduction of two eccentricities $e_{i}^{y}, e_{i}^{z}$ and two stiffness springs $k_{i}^{y}, k_{i}^{z}$ at node $i$.

The local element reference is $(\mathbf{x}, \mathbf{y}, \mathbf{z})$, where $\mathbf{x}$ is the beam element axis. $\mathscr{N}_{i}, \mathscr{V}_{i}^{y}, \mathscr{V}_{i}^{z}, \mathscr{M}_{i}^{y}$, $\mathscr{M}_{i}^{z}$ and $\mathscr{M}_{i}^{x}$ are, respectively, the axial force, the shear stresses along the $\mathbf{y}$ and $\mathbf{z}$ axes, the bending momenta in the $\mathbf{y}$ and $\mathbf{z}$ planes, and the torque at node $i$ of the finite element. The dual variables are the usual displacements and rotations at the nodes: $U_{i}^{x}, U_{i}^{y}, U_{i}^{z}, \Omega_{i}^{x}, \Omega_{i}^{y}, \Omega_{i}^{z}$. The length of the beam is denoted by $l$, EI is the flexural rigidity along the $\mathbf{x}$-axis, ES is the axial stiffness and GJ the torsion stiffness along the $\mathbf{x}$-axis. $E$ is Young's modulus and $G$ the shear modulus. The beams are tubes with external diameter $\phi_{1}$ and thickness $t$.
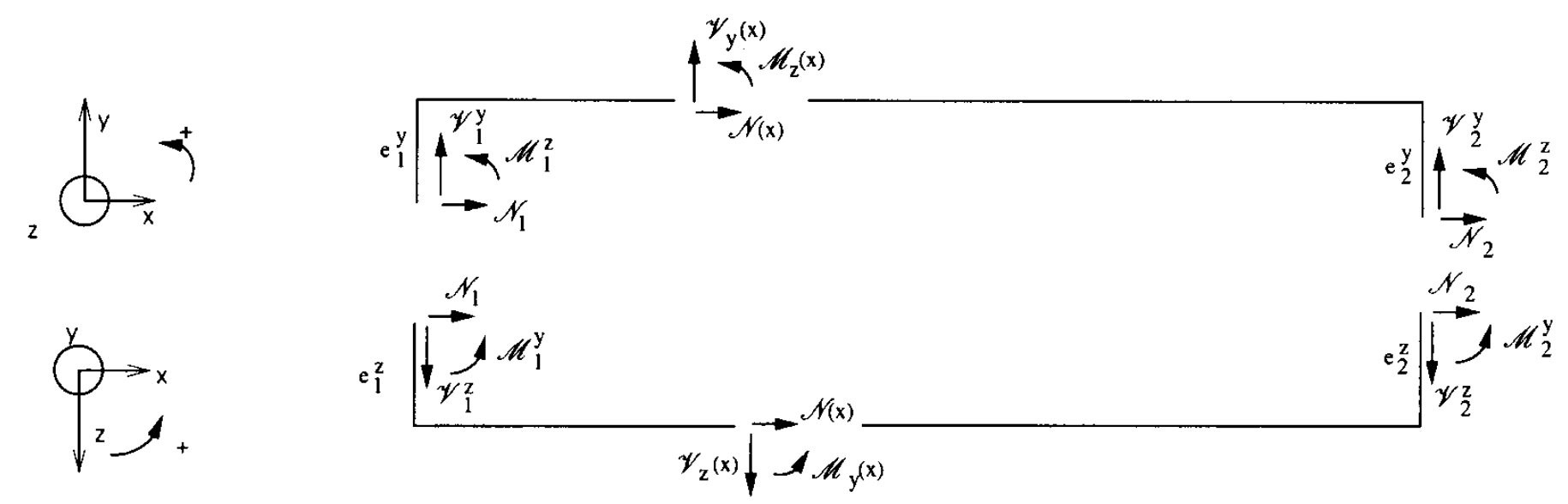

Figure 2. External nodal forces and internal forces applied to the beam. 


\subsection{Computation of the matrix $B$}

The static equilibrium of the beam leads to:

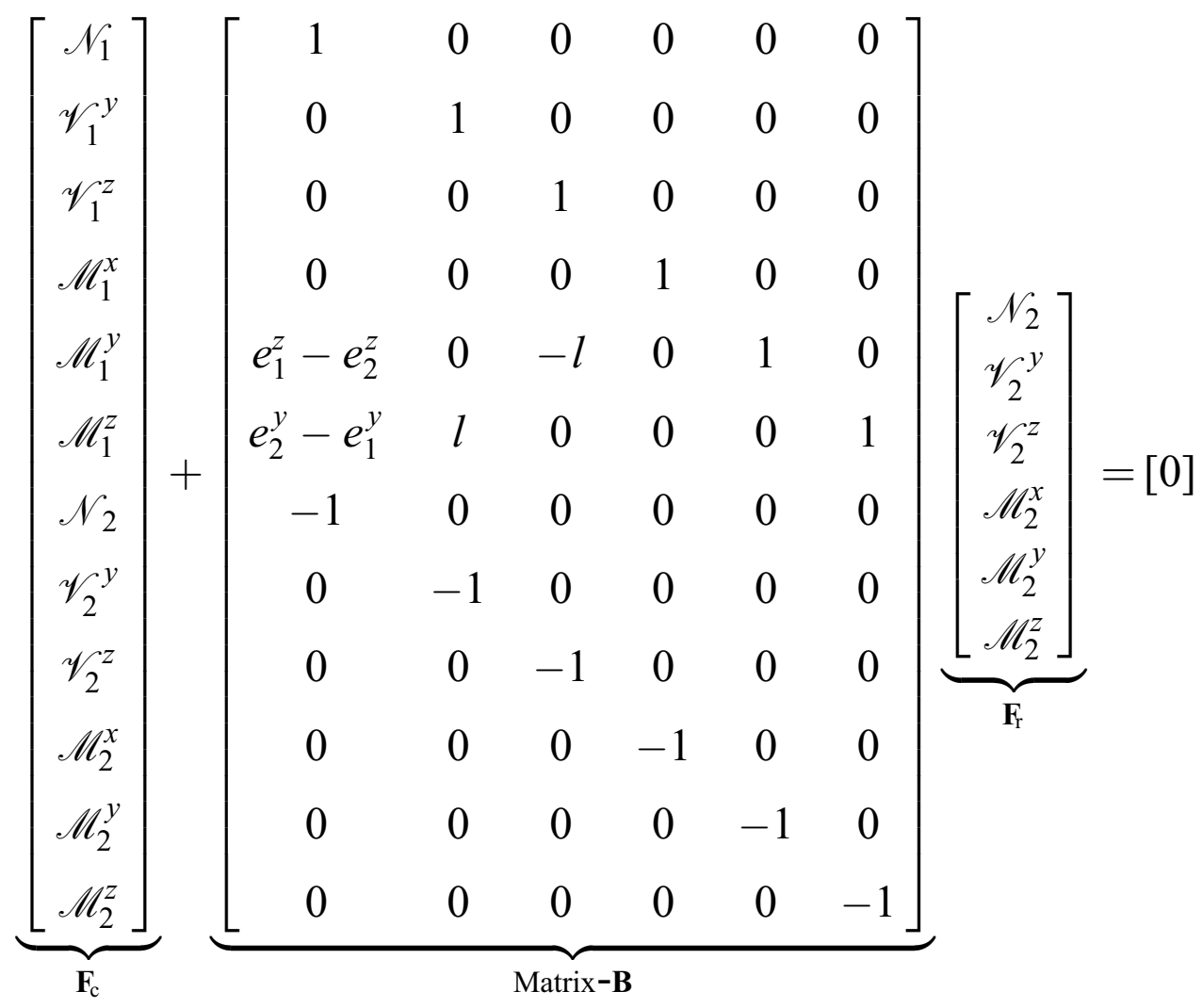

\subsection{Internal forces}

The internal forces are denoted as follows: $\mathscr{N}(x)$ is the axial force, $\mathscr{M}^{y}(x)$ and $\mathscr{M}^{z}(x)$ are the bending momenta in the $\mathbf{y}$ and $\mathbf{z}$ planes, $\mathscr{V}^{y}(x)$ and $\mathscr{V}^{z}(x)$ are the shear stresses along the $\mathbf{y}$-and $\mathbf{z}$-axis, and finally $\mathscr{M}^{x}(x)$ is the torque along the $\mathbf{x}$-axis, see Figure 2 . The equilibrium of a part of the beam gives the shape force functions:

$$
\left[\begin{array}{c}
\mathscr{N}(x) \\
\mathscr{V}^{y}(x) \\
\mathscr{V}^{z}(x) \\
\mathscr{M}^{x}(x) \\
\mathscr{M}^{y}(x) \\
\mathscr{M}^{z}(x) \\
\mathscr{M}_{1}^{y} \\
\mathscr{M}_{1}^{z} \\
\mathscr{M}_{2}^{y} \\
\mathscr{M}_{2}^{z}
\end{array}\right]=\left[\begin{array}{c}
\mathbf{N}_{1}(x) \\
\mathbf{N}_{2}(x) \\
\mathbf{N}_{3}(x) \\
\mathbf{N}_{4}(x) \\
\mathbf{N}_{5}(x) \\
\mathbf{N}_{7}(x) \\
\mathbf{N}_{8}(x) \\
\mathbf{N}_{9}(x) \\
\mathbf{N}_{10}(x)
\end{array}\right] \mathbf{F}_{\mathrm{r}}=\left[\begin{array}{cccccc}
1 & 0 & 0 & 0 & 0 & 0 \\
0 & 1 & 0 & 0 & 0 & 0 \\
0 & 0 & 1 & 0 & 0 & 0 \\
0 & 0 & 0 & 1 & 0 & 0 \\
-e_{2}^{z} & 0 & x-l & 0 & 1 & 0 \\
e_{2}^{y} & l-x & 0 & 0 & 0 & 1 \\
e_{2}^{z}-e_{2}^{z} & 0 & -l & 0 & 1 & 0 \\
e_{2}^{y}-e_{1}^{y} & l & 0 & 0 & 0 & 1 \\
0 & 0 & 0 & 0 & 1 & 0 \\
0 & 0 & 0 & 0 & 0 & 1
\end{array}\right] \mathbf{F}_{\mathrm{r}}
$$




\subsection{Strain energy, compliance and stiffness matrix}

The total complementary strain energy is

$$
\begin{aligned}
\mathscr{E}_{\text {ISO }}^{c}= & \frac{1}{2} \int_{0}^{l} \frac{\mathscr{N}^{2}(x)}{\mathrm{ES}} \mathrm{d} x+\frac{1}{2} \int_{0}^{l} \frac{\mathscr{M}^{x^{2}}(x)}{\mathrm{GJ}} \mathrm{d} x+\frac{1}{2} \int_{0}^{l} \frac{\mathscr{M}^{y^{2}}(x)}{\mathrm{EI}} \mathrm{d} x+\frac{1}{2} \int_{0}^{l} \frac{\mathscr{M}^{z^{2}}(x)}{\mathrm{EI}} \mathrm{d} x \\
& +\frac{1}{2} \frac{\mathscr{M}_{1}^{y^{2}}}{k_{1}^{y}}+\frac{1}{2} \frac{\mathscr{M}_{2}^{y^{2}}}{k_{2}^{y}}+\frac{1}{2} \frac{\mathscr{M}_{1}^{z^{2}}}{k_{1}^{z}}+\frac{1}{2} \frac{\mathscr{M}_{2}^{z^{2}}}{k_{2}^{z}}
\end{aligned}
$$

The associated isostatic compliance matrix of the finite element $\mathbf{K}_{\mathrm{r}}$ is therefore

$$
\left[\begin{array}{cccccc}
s_{1} & \frac{l^{2} e_{2}^{y}}{2 \mathrm{EI}}+\frac{l\left(-e_{1}^{y}+e_{2}^{y}\right)}{k_{1}^{z}} & \frac{l^{2} e_{2}^{z}}{2 \mathrm{EI}}+\frac{l\left(-e_{1}^{z}+e_{2}^{z}\right)}{k_{1}^{y}} & 0 & -\frac{l e_{2}^{z}}{\mathrm{EI}}+\frac{e_{1}^{z}-e_{2}^{z}}{k_{1}^{y}} & \frac{l e_{2}^{y}}{\mathrm{EI}}+\frac{-e_{1}^{y}+e_{2}^{y}}{k_{1}^{z}} \\
\frac{l^{2} e_{2}^{y}}{2 \mathrm{EI}}+\frac{l\left(-e_{1}^{y}+e_{2}^{y}\right)}{k_{1}^{z}} & \frac{l^{3}}{3 \mathrm{EI}}+\frac{l^{2}}{k_{1}^{z}} & 0 & 0 & 0 & \frac{l}{k_{1}^{z}}+\frac{l^{2}}{2 \mathrm{EI}} \\
\frac{l^{2} e_{2}^{z}}{2 \mathrm{EI}}+\frac{l\left(-e_{1}^{z}+e_{2}^{z}\right)}{k_{1}^{y}} & 0 & \frac{l^{3}}{3 \mathrm{EI}}+\frac{l^{2}}{k_{1}^{y}} & 0 & -\frac{l}{k_{1}^{y}}-\frac{l^{2}}{2 \mathrm{EI}} & 0 \\
0 & 0 & 0 & \frac{l}{\mathrm{GJ}} & 0 & 0 \\
-\frac{l e_{2}^{z}}{\mathrm{EI}}+\frac{e_{1}^{z}-e_{2}^{z}}{k_{1}^{y}} & 0 & -\frac{l}{k_{1}^{y}}-\frac{l^{2}}{2 \mathrm{EI}} & 0 & \frac{1}{k_{1}^{y}}+\frac{1}{k_{2}^{y}}+\frac{l}{\mathrm{EI}} & 0 \\
\frac{l e_{2}^{y}}{\mathrm{EI}}+\frac{-e_{1}^{y}+e_{2}^{y}}{k_{1}^{z}} & \frac{l}{k_{1}^{z}}+\frac{l^{2}}{2 \mathrm{EI}} & 0 & 0 & 0 & \frac{1}{k_{1}^{z}}+\frac{1}{k_{2}^{z}}+\frac{l}{\mathrm{EI}}
\end{array}\right]
$$

with

$$
s_{1}=\frac{l}{\mathrm{ES}}+\frac{l e_{2}^{y^{2}}}{\mathrm{EI}}+\frac{l e_{2}^{z^{2}}}{\mathrm{EI}}+\frac{\left(-e_{1}^{y}+e_{2}^{y}\right)^{2}}{k_{1}^{z}}+\frac{\left(e_{1}^{z}-e_{2}^{z}\right)^{2}}{k_{1}^{y}}
$$

The matrix $\mathbf{K}_{\mathrm{c}}=\mathbf{B} \mathbf{K}_{\mathrm{r}} \mathbf{B}^{\mathrm{T}}$ is numerically computed.

\section{IDENTIFICATION OF THE MODEL PARAMETERS}

\subsection{Global procedure}

Let us consider the case of a T-joint, clamped at both ends and loaded at the end of the cracked element (Figure 3). It is assumed that only one through-crack exists, located at the connection, near the $(\mathbf{y}, \mathbf{z})$ plane and is supposed to be symmetrical $((\mathbf{x}, \mathbf{y})$ plane $)$. Its length is parametered by the angle $2 \varphi$. The aim is to find the mechanical parameters, here $e=e_{1}^{y}$ and $k=k_{1}^{z}$, depending on $\varphi$. A numerical experience for the fundamental loading cases is obtained from a local model (a three-dimensional mesh using thick quadratic shell elements). The brace 


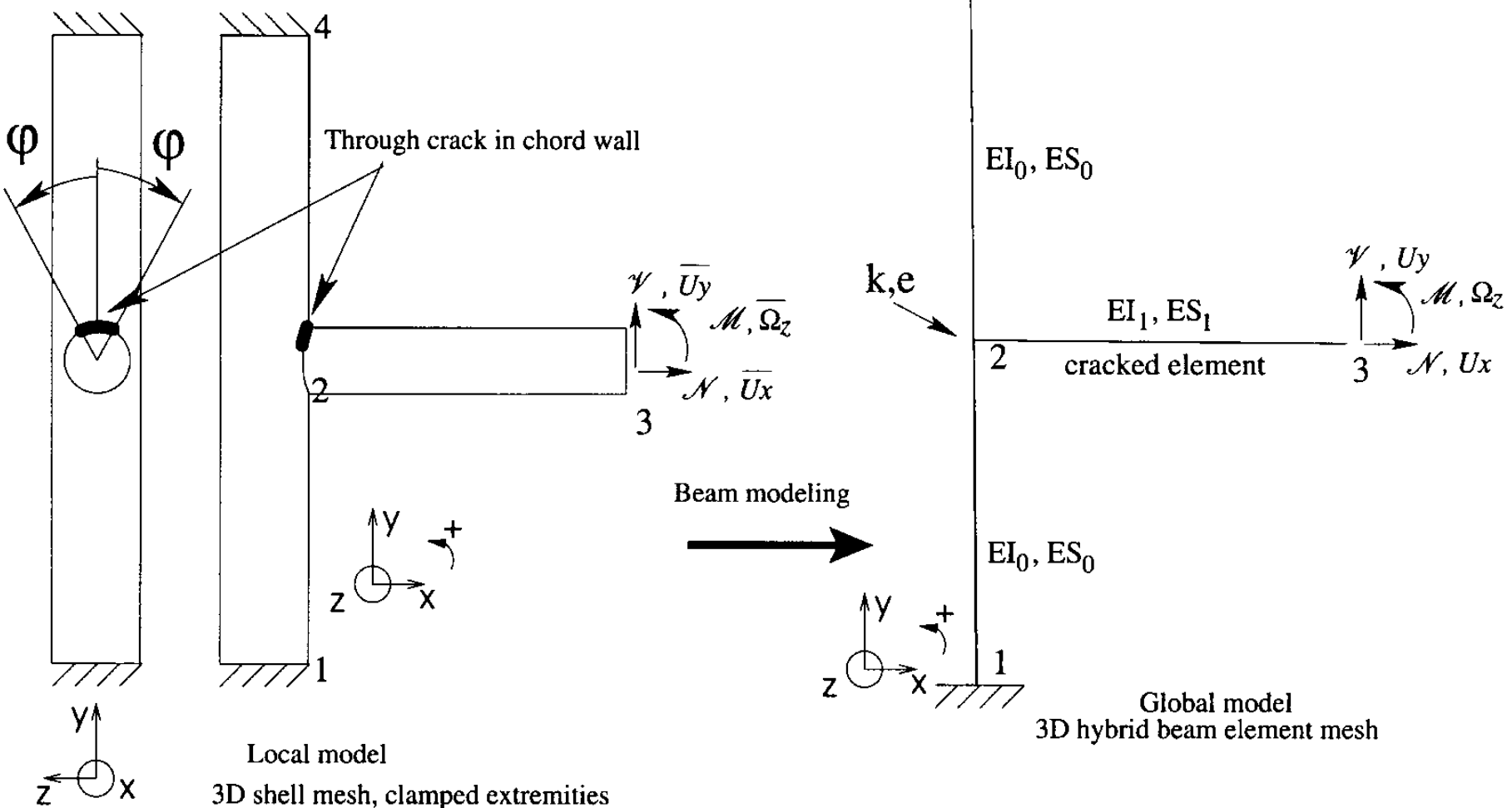

Figure 3. Modelling procedure.

tube is taken sufficiently long, so that local ovalization would not affect the displacements at the brace extremity.

Let us denote by $\overline{\mathbf{U}}$ the displacement vector and $\mathbf{F}$ the force vector at node 3 of the cracked tube for the local model. Regarding the beam model, $\mathbf{U}$ is the displacement vector at node 3, the compliance matrix is $\mathbf{S}=\mathbf{S}(e, k)$, and the relationship between displacements and external forces of the beam finite element model is

$$
\mathbf{U}=\mathbf{S F}
$$

We look for minimizing the difference between the two displacement vectors $\overline{\mathbf{U}}$ and $\mathbf{U}$ :

$$
\min _{e, k} Q, \quad Q=(\mathbf{U}-\overline{\mathbf{U}})^{2}
$$

$Q$ is minimal with respect to $e$ and $k$ when

$$
\frac{\partial Q}{\partial e}=0, \quad \frac{\partial Q}{\partial k}=0
$$

Remembering that the operator $\mathbf{S}$ and its derivatives are symmetric, the optimization problem leads to the following equations:

$$
\begin{aligned}
& \mathbf{F}^{\mathrm{T}}\left[\mathbf{S} \frac{\partial \mathbf{S}}{\partial e}+\frac{\partial \mathbf{S}}{\partial e} \mathbf{S}\right] \mathbf{F}-2 \overline{\mathbf{U}}^{\mathrm{T}}\left[\frac{\partial \mathbf{S}}{\partial e}\right] \mathbf{F}=0 \\
& \mathbf{F}^{\mathrm{T}}\left[\mathbf{S} \frac{\partial \mathbf{S}}{\partial k}+\frac{\partial \mathbf{S}}{\partial k} \mathbf{S}\right] \mathbf{F}-2 \overline{\mathbf{U}}^{\mathrm{T}}\left[\frac{\partial \mathbf{S}}{\partial k}\right] \mathbf{F}=0
\end{aligned}
$$


For the beam model, one has to compute the compliance matrix $\mathbf{S}$ as defined in Equation (20). This can be achieved by static condensation of the full stiffness matrix $\mathbf{K}_{\text {tot }}$ :

$$
\mathbf{K}_{\text {tot }} \mathbf{U}_{\text {tot }}=\left[\begin{array}{llll}
\mathbf{K}_{11} & \mathbf{K}_{12} & \mathbf{K}_{13} & \mathbf{K}_{14} \\
\mathbf{K}_{21} & \mathbf{K}_{22} & \mathbf{K}_{23} & \mathbf{K}_{24} \\
\mathbf{K}_{31} & \mathbf{K}_{32} & \mathbf{K}_{33} & \mathbf{K}_{34} \\
\mathbf{K}_{41} & \mathbf{K}_{42} & \mathbf{K}_{43} & \mathbf{K}_{44}
\end{array}\right]\left[\begin{array}{c}
0 \\
\mathbf{U}_{2} \\
\mathbf{U}_{3} \\
0
\end{array}\right]=\left[\begin{array}{c}
\mathbf{F}_{1} \\
0 \\
\mathbf{F}_{3} \\
\mathbf{F}_{4}
\end{array}\right]
$$

where $\mathbf{U}_{i}$ and $\mathbf{F}_{i}$ are, respectively, the displacement vector and the force vector at node $i$. One finally finds that

$$
\mathbf{S}=\left[\mathbf{K}_{33}-\mathbf{K}_{32} \mathbf{K}_{22}^{-1} \mathbf{K}_{23}\right]^{-1}
$$

In order to have homogeneous terms in Equation (23), the reduced variables $\mathscr{M}^{*}$ and $\Omega^{*}$ must be used in the optimization problem:

$$
\begin{gathered}
\mathscr{M}^{*}=\frac{\mathscr{M}}{l} \\
\Omega^{*}=\Omega l
\end{gathered}
$$

\subsection{Closed-form solution for the parameters $(e, k)$}

The crack is located at node 2 in the T-joint. The loss of stiffness occurs at this node. The 1-2 and 2-4 elements are classical beams, clamped at nodes 1 and 4, and the 2-3 element is the new finite element. The external forces at node 3 and their dual variables are defined as follows:

$$
\mathbf{F}=\left[\begin{array}{c}
\mathscr{N} \\
\mathscr{V} \\
\mathscr{M}
\end{array}\right], \quad \mathbf{U}=\left[\begin{array}{c}
U_{x} \\
U_{y} \\
\Omega_{z}
\end{array}\right]
$$

The global compliance matrix $\mathbf{S}$ of this structure is

$$
\left[\begin{array}{ccc}
\frac{e^{2}}{k}+\frac{l}{\mathrm{ES}_{1}}+\frac{l^{3}}{24 \mathrm{EI}_{0}}+\frac{l e^{2}}{8 \mathrm{EI}_{0}} & -\frac{l e}{k}-\frac{l^{2} e}{8 \mathrm{EI}_{0}} & -\frac{l e}{k}-\frac{l^{2} e}{8 \mathrm{EI}_{0}} \\
-\frac{l e}{k}-\frac{l^{2} e}{8 \mathrm{EI}_{0}} & \frac{l^{2}}{k}+\frac{l}{2 \mathrm{ES}_{0}}+\frac{l^{3}}{8 \mathrm{EI}_{0}}+\frac{l^{3}}{3 \mathrm{EI}_{1}} & \frac{l^{2}}{k}+\frac{l^{3}}{8 \mathrm{EI}_{0}}+\frac{l^{3}}{2 \mathrm{EI}_{1}} \\
-\frac{l e}{k}-\frac{l^{2} e}{8 \mathrm{EI}_{0}} & \frac{l^{2}}{k}+\frac{l^{3}}{8 \mathrm{EI}_{0}}+\frac{l^{3}}{2 \mathrm{EI}_{1}} & \frac{l^{2}}{k}+\frac{l^{3}}{8 \mathrm{EI}_{0}}+\frac{l^{3}}{\mathrm{EI}_{1}}
\end{array}\right]
$$

Using (23), exact analytical solutions are obtained for the parameters $e$ and $k$ when the three fundamental loading cases are supposed to be applied. 
- When $\mathscr{N}$ is applied, the parameters are

$$
e=\frac{\mathscr{N}\left[\frac{l}{\mathrm{ES}_{1}}+\frac{l^{3}}{24 \mathrm{EI}_{0}}\right]-\bar{U}_{x}}{\frac{\bar{U}_{y}+\bar{\Omega}_{z}^{*}}{2 l}}, \quad k=\frac{\mathscr{N}\left[\bar{U}_{x}-\mathscr{N}\left[\frac{l}{\mathrm{ES}_{1}}+\frac{l^{3}}{24 \mathrm{EI}_{0}}\right]\right]}{\left[\frac{\bar{U}_{y}+\bar{\Omega}_{z}^{*}}{2 l}\right]^{2}-\frac{\mathscr{N} l}{8 \mathrm{EI}_{0}}\left[\bar{U}_{x}-\mathscr{N}\left[\frac{l}{\mathrm{ES}_{1}}+\frac{l^{3}}{24 \mathrm{EI}_{0}}\right]\right]}
$$

- When $\mathscr{V}$ is applied, the parameters are

$$
e=\frac{-\bar{U}_{x}}{\frac{\bar{U}_{y}+\bar{\Omega}_{z}^{*}}{2 l}-\frac{\mathscr{V}}{l}\left[\frac{5 l^{3}}{12 \mathrm{EI}_{1}}+\frac{l}{4 \mathrm{ES}_{0}}\right]}, \quad k=\frac{\mathscr{V} l}{\frac{\bar{U}_{y}+\bar{\Omega}_{z}^{*}}{2 l}-\frac{\mathscr{V}}{l}\left[\frac{5 l^{3}}{12 \mathrm{EI}_{1}}+\frac{l^{3}}{8 \mathrm{EI}_{0}}+\frac{l}{4 \mathrm{ES}_{0}}\right]}
$$

- When $\mathscr{M}$ is applied, the parameters are

$$
e=\frac{-\bar{U}_{x}}{\frac{\bar{U}_{y}+\bar{\Omega}_{z}^{*}}{2 l}-\mathscr{M}^{*} \frac{3 l^{2}}{4 \mathrm{EI}_{1}}}, \quad k=\frac{\mathscr{M}^{*} l}{\frac{\bar{U}_{y}+\bar{\Omega}_{z}^{*}}{2 l}-\mathscr{M}^{*}\left[\frac{3 l^{2}}{4 \mathrm{EI}_{1}}+\frac{l^{2}}{8 \mathrm{EI}_{0}}\right]}
$$

\section{RESULTS}

Let us take the following values (typical of offshore jacket structures) for the previous problem identification: $l=19.2 \mathrm{~m}, E=210 \mathrm{GPa}$. For tubes $1-2$ and $2-4$ we set $\phi_{1}=1.1 \mathrm{~m}, t=0.05 \mathrm{~m}$, and for tubes 2-3: $\phi_{1}=0.55 \mathrm{~m}, t=0.02 \mathrm{~m}$. The external forces $\mathscr{N}, \mathscr{V}$ and $\mathscr{M}$ are equal to $100(\mathrm{kN}, \mathrm{kNm})$. When looking carefully at the identification based on axial load $\mathscr{N}$, it gives poor results since it does not properly represent the local mechanical behaviour of the cracked node. Hence, it is not used. For various crack lengths, we obtain the following results (Figure 4).

The parameters $e$ and $k$ should depend on the crack length, but not on external loadings: the more accurate the mechanical model, the more closer the $e, k$ curves for $\mathscr{M}$ and $\mathscr{V}$ should be to one another. These curves show that for small cracks length, the mechanical model is not as satisfactory as expected but still gives correct results. For large crack sizes, the model gives very good results, as both the curves for $e$ and $k$, and for $\mathscr{M}$ and $\mathscr{V}$ do merge.

\section{CONCLUSIONS}

A new beam finite element is presented to model the behaviour of through-cracked tubular nodes. Its construction is based on a complementary variational formulation, leading to a hybrid-type element. It is built on a mechanical model, giving physical sense to the parameters. 


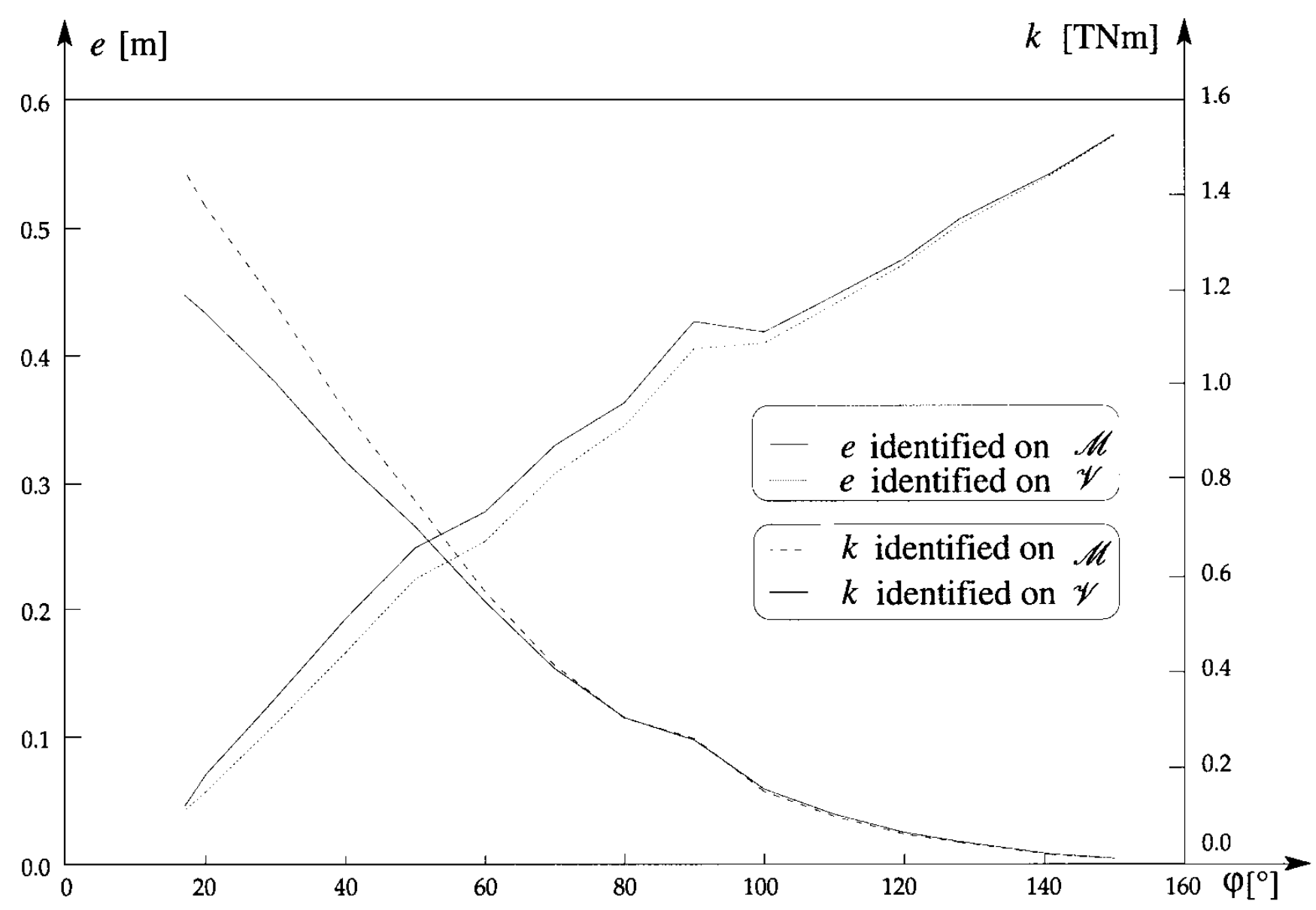

Figure 4. Evolution of parameters $e$ and $k$ as a function of crack length parameter $\varphi$.

Their identification is done by exact analytic formulas, and at most eight parameters are needed for the complete finite element. It exhibits excellent accuracy characteristics for all loading cases, particularly for very large cracks. This element is very useful for large structure modelling because of the fast computational time compared to that needed for a local shell meshing.

\section{REFERENCES}

1. Chen T-Y, Zhang H-Y. Stress analysis of spatial frames with consideration of local flexibility of multiplanar tubular joint. Engineering Structures 1996; 18(6):465-471.

2. Lixian Y, Tieyun C, Shuiyun W. Local flexibility behavior of tubular joints and its effect on global analysis of tubular structures. China Ocean Engineering 1990; 4(4):371-384.

3. Tieyun C, Huiyuan Z. Local joint flexibility multibrace tubular joints. China Ocean Engineering 1993; 7(2): $125-138$.

4. Dover WD, Dharmavasan S, Brennan FP, Marsh KJ (eds). Fatigue Crack Growth in Offshore Structures. EMAS, 1995.

5. Lieurade HP, Gerald JP, Putot CJ. Fatigue life prediction of tubular nodes. In Offshore Technology Conference, No. OTC 3699, May 1980.

6. Fraeijs de Veubeke BM. Stress Analysis. Wiley: New York, 1965.

7. Imbert JF. Analyse des Structures par Éléments Finis. Cépaduès Éditions, Toulouse, (3rd edn), 1991. 